\title{
ON CONNECTION OF VARIATIONS BETWEEN HARD COSMIC RAY FLUX, TEMPERATURE AND CARDIOVASCULAR DISEASES IN VILNIUS AND SUNSPOT NUMBER DURING 2001-2012
}

\author{
Dmitrijus STYRO ${ }^{\mathrm{a}}$, Ana USOVAITE ${ }^{\mathrm{b}}$ \\ ${ }^{a}$ Department of Physics, Vilnius Gediminas Technical University, Sauletekio al. 11, LT-10223 Vilnius, Lithuania \\ ${ }^{b}$ Department of Graphical Systems, Vilnius Gediminas Technical University, Sauletekio al. 11, \\ LT-10223 Vilnius, Lithuania
}

Submitted 18 Apr. 2014; accepted 14 Jan. 2015

\begin{abstract}
The connection has been found between the course of cardiovascular diseases (CVD) and the hard cosmic ray flux (HCRF) near the ground surface in Vilnius. The course of air temperature and number of sunspot was simultaneously considered. The investigation was carried out for the average annual and average monthly values in the period of solar cycle 2001-2012. The course of average annual data is most identical for HCRF and number of sunspot: whereas, it significantly differs from CVD and temperature course. The stable connection between a course of average monthly values of HCRF and CVD is found. Such a connection for temperature and CVD had a negative correlation with coefficient of correlation -0.9. A rather weak correlation was between the change in the number of sunspots and other characteristics. Values of correlation coefficient between them were less than 0.4 during all of the solar cycle 2001-2012. The exception had taken place at the maximum solar activity, i. e. in 2001 and 2012 when values of correlation coefficient exceeded 0.5 . For the short-term prognosis of CVD leaps exceeding average monthly value by $10 \%$ in 1-3 days after HCRF decrease according to the proposed criterion, the high efficiency of the results $68-79 \%$ was obtained. The variation of sunspot number isn't connected with these data. A short-term connection between the change in air temperature, the change in the sunspot number and CVD leaps has not been found. The human factor has an additional influence on CVD leaps, which was considered in these studies.
\end{abstract}

Keywords: hard cosmic ray flux, sunspots, temperature, cardiovascular diseases, correlation, human factor, environment monitoring.

\section{Introduction}

The impact of meteorological, geophysical and cosmic factors on the human body has been widely discussed in the literature. Change in the various natural phenomena can negatively affect human health. These factors may occur because of frequent changes of atmospheric pressure, temperature, humidity and etc. (Houck et al. 2005; Ferrari et al. 2012; Martin et al. 2012), as well as cosmic phenomena associated with fluctuations in solar activity that affect the geomagnetic field (Chizhevsky 1976). The mechanism for the negative energy transfer to people is complex. In general, such a transfer often occurs simultaneously from a number of processes; however to find the main one is difficult. In practice it is necessary to apply statistical methods of the analysis of observation results that have various characteristics of external influence.
Therefore a definition of connection, for instance, in cardiovascular diseases (CVD) number and other factor from various sources, have the average values for comparison of the processes during a long and a short period of time.

It is natural that comparison of average annual data allows to define a tendency of the course of obtained results.

A more detailed study into the interrelation of the same characteristics for a shorter period of time (average monthly) revealed, the other regularities of their variations were found. Here in particular, it is necessary to take into account the seasons of a year, which can significantly affect the course of the analysis of experimental data.

The investigations of external impact on a human body becomes the most perspective in the case of their practical use. 
For this purpose it is necessary to carry out a detailed analysis of various factors variation leading to human organism disorder within several days. Various sources can impact on human health individually or together at the same time.

In the case of a long continuous exposure to one of the factors, a health of a person initially worsens, and later the organism adapts and ceases to react.

One of the main external sources influencing human organism is variable solar activity. However, its impact is not transmitted directly to the person and occurs on complex way. So, a large-scale solar magnetic field, extending in a cosmic space, influences a geomagnetic field. Besides, solar flares in the form of corpuscular flux also affect the geomagnetic field. Instability of one process results in instability of others, i.e. solar influence leads to variations of the geomagnetic field, which impact on a person.

The Earth continuously receives cosmic particles from the Galaxy. As far as most of these particles transfer an electric charge and penetrating into a geomagnetic field they change their original energy. Therefore, these changes of energy depend on change of an induction of geomagnetic field. The Earth's surface reaches only secondary cosmic rays - a flux of muons and gamma quanta, which are formed after the interaction of primary cosmic rays with molecules of atmospheric gases (Styro et al. 2004).

Thus, their fluctuations reflect variations of the geomagnetic field at a ground surface, being its indirect indicator. Therefore the impact of variations in geomagnetic field on the human organism can be identified and even predicted by the fluctuations of the secondary cosmic ray flux. For this purpose it is suitable only hard cosmic ray component, because influence of the soft component is possible by non-cosmic factors (Palmer et al. 2006).

The effect of the geomagnetic field near the ground surface is registered after the variation of hard cosmic ray flux (HCRF). Therefore, HCRF variations predict a course of an induction of geomagnetic field which affects the human body. As far as the perception of such effect has a some "inertia", then the worsening of human health occurs within a certain time. Therefore the variation of HCRF can predict the changes in his organism. In general, the worsening of human health is observed after 1-3 days in HCRF variations (Styro et al. 2005).

In addition to the impact of the geomagnetic field on human health, there are other sources in particular, biological character, meteorological processes - variations of temperature and humidity of air, instability of atmospheric pressure and etc., which often occur simultaneously with the variation of geomagnetic field (Styro et al. 2007; Ferrari et al. 2012; Stoupel et al. 2012; Martin et al. 2012; Hiltunen et al. 2012; McGuinn et al. 2013; Lim et al. 2013). Intensive dynamic and thermal processes in the atmosphere change density of the air, which are connected with the movement of cyclonic and anti-cyclonic formations. Change of air density leads to the change of a vertical flux of muons. Therefore, the variation of the muon flux (secondary cosmic rays) can characterize the instability of atmospheric processes (Styro et al. 2008, 2011), also affect human health. In this paper, the deterioration of human health is considered only as the leaps of cardiovascular diseases (CVD). Therefore, the changes of meteorological processes have to be taken into account to predict CVD leaps by HCRF variation.

There are also simultaneous additional affects on the human body as well as the electromagnetic instability in the atmosphere and the Earth's crust. There is no consensus about the connection between impact of these factors on people with cardiovascular pathology. However, in some studies, the authors show the empirical relationship between them (Bi et al. 2011; Styro et al. 2005). The increase of lethal outcomes of people with cardiovascular pathology is observed during strong variation of a geomagnetic field (Dimitrova et al. 2009; Rodriquez-Taboada et al. 2004; Vencloviene et al. 2013). It is also shown that increase of lethal cases coincide with instability of protons flux in the galactic cosmic rays in the cases where their energy is greater than $90 \mathrm{MeV}$ (Dimitrova et al. 2009). The results of these observations took place for global scale during the long period of time. An increasing number of CVD and fatal cases were also observed at abnormally high geomagnetic activity and magnetic storms (Chizhevsky 1976; Breus et al. 2012; Palmer et al. 2006; Rodriquez-Taboada et al. 2004; Styro et al. 2005).

In the above mentioned situations HCRF variations occur simultaneously. It is found that after HCRF decrease, the CVD leaps take place (Styro et al. 2005, 2009). Therefore, the study of external influences on the human body are the most promising, when their results are applied in practice. For this purpose, there is a need for a detailed analysis of short-term HCRF (or geomagnetic field) and meteorological parameters variations taking into account the solar activity, which resulted in a deterioration of human health. In a present work a deterioration of human health increase only by cardiovascular diseases is implied. To prove that above mentioned results haven't an accidental character it is necessary to carry out the long-term observations. Such investigation is represented in the present work, where comparative analysis of average annual and average monthly values was carried out during solar cycle 2001-2012. The various sources can affect the human body at the same time. So, the comprehensive studies of above stated factors are necessary to predict the possible negative effects of external influences on human health.

\section{Materials and methods}

Data on HCRF were obtained by the gamma-spectrometer with a scintillation detector $(\mathrm{NaI}(\mathrm{Tl})$ crystal at the laboratory 
of Nuclear Hydrophysics of the Vilnius Gediminas Technical University. The detector was placed in a lead protective chamber with walls $10-12 \mathrm{~cm}$ thick to absorb the mild component of cosmic radiation (Styro et al. 2005).

The integral number of registered cosmic particles with energy from 300 to $\infty \mathrm{keV}$ formed the spectrum by the interaction of HCRF with the detector following Compton's scattering. The operating stability of the gamma-spectrometer was controlled by the radionuclide ${ }^{137} \mathrm{Cs}$. HCRF measurements were carried out continuously and the data were registered every $15 \mathrm{~min}$. The measurement error was $1 \%$.

Deviation from the average monthly value of HCRF exceeding the mentioned error during exposure time of $1 \mathrm{~h}$ were due to the external action on the gamma-spectrometer concerning the analysis of obtained results. About 430000 measurement results were analysed.

Data on CVD were collected over 144 months (20012012) from Vilnius ambulance service. During this period there were about 250000 CVD-related ambulance callouts. The sunspot number was taken into consideration (Sunspot data files 2013). The cyclonic and anticyclonic situations were analysed too.

The present study was restricted to time periods when the cosmophysical, meteorological and medical data could be compared. For statistical analysis, the correlation coefficients were used for comparing daily HCRF variations and CVD increases over 1-3 days. The correlation coefficients calculation results and their accuracy definition between above mentioned characteristics had taken place. At the reliability of 0.95 the maximum relative error of correlation coefficients data was 3\%. Probabilities of $95 \%$ were considered significant, $65-75 \%$ being indicative of strong trends.

\section{Results}

The present investigations relate to the local phenomena, determining HCRF instability and follow on for them CVD leaps. It is found out that the leaps of CVD observed after decrease of HCRF under appropriate condition (Styro et al. 2005). However, the leaps of CVD may be influenced by other factors. Therefore the additional studying of variations of the most probable physical parameters which also can be connected with external impact on human body, was carried out.

Such studies took place during the solar cycle 20012012. Measurements and processing of the experimental results were carried out as follows:

1. Registration of impulses number generated by the flux of cosmic particles every 15 minutes in the energy range from $300 \mathrm{keV}$ to $\infty$ was brought into a $1 \mathrm{~h}$ time interval.

2. A decrease in HCRF values (more then 200 impulses) for a $4 \mathrm{~h}$ period during any day was used as the threshold value for selection.

3. A correlation between HCRF decrease and increase in CVD number, exceeding the monthly average value by $10 \%$ and more within $1-3$ days was determined.

4. Information on meteorological situations was obtained from the Lithuanian Hydrometeorological Service.

5. Information on solar flares was taken from the National Geophysical Data Center (NGDC) web site.

6. The age of people is not taken into account.

First of all the average physical parameters, i.e. HCRF, temperature, sunspot number and CVD were investigated.

It turned out that the course of the average annual values of HCRF agrees well with the course of the sunspot number (Fig. 1) and significantly differs from a course of average annual air temperature in Vilnius (Figs 1,2). The course of average annual values of CVD (Fig. 2) is another and doesn't agree with course of above mentioned physical parameters (Figs 1, 2).

However, comparing the average monthly values course of the same characteristics an another situation takes place. In this case the data of HCRF and CVD course are identical and the temperature course at the same time in Vilnius is opposite (Figs 3, 4). But there is no such connection between a course of above mentioned parameters and the monthly average values of sunspots (Figs 3, 4).

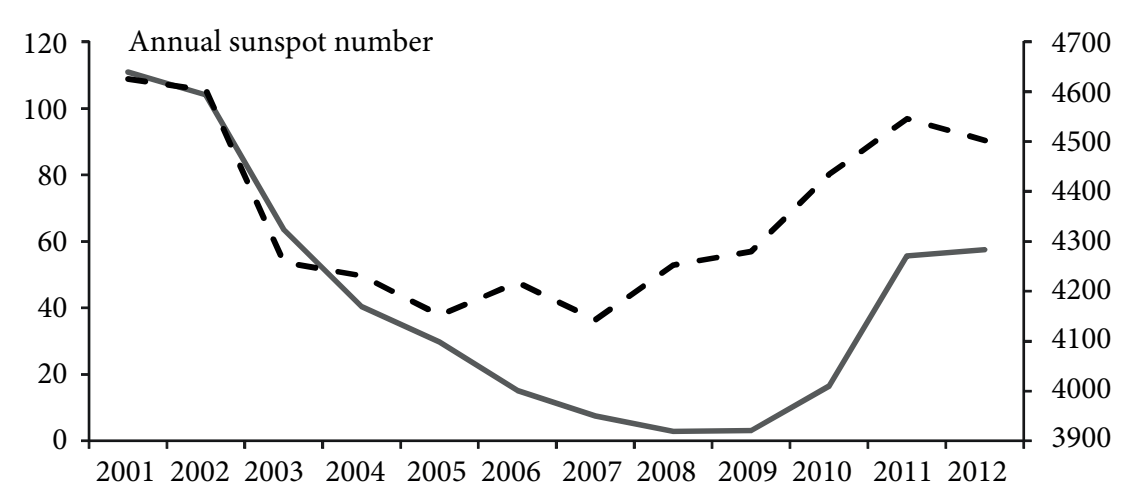

Fig. 1. Annual average values in 2001-2012: sunspots (-), hard cosmic ray flux in Vilnius (-----) 


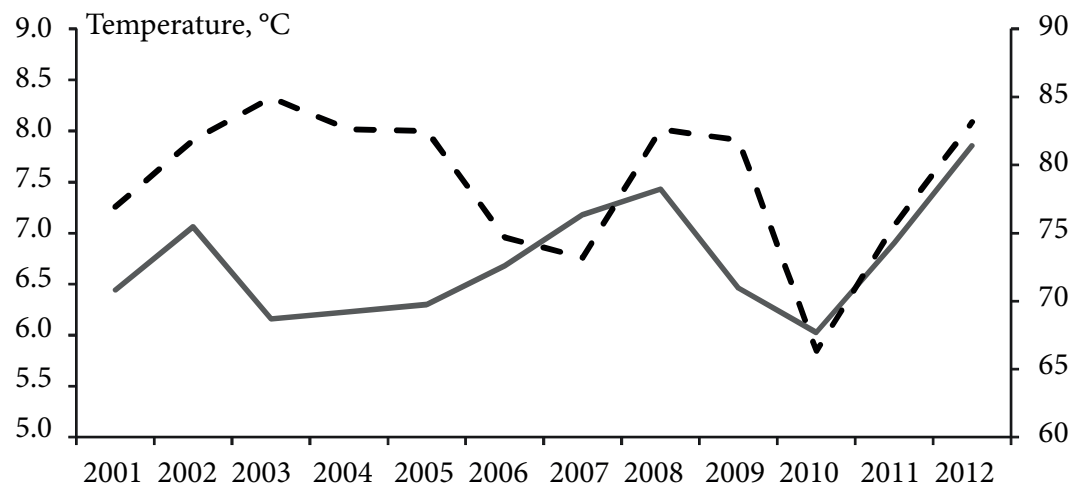

Fig. 2. Annual average values in 2001-2012 in Vilnius: cardiovascular diseases (-----), temperature $(-)$

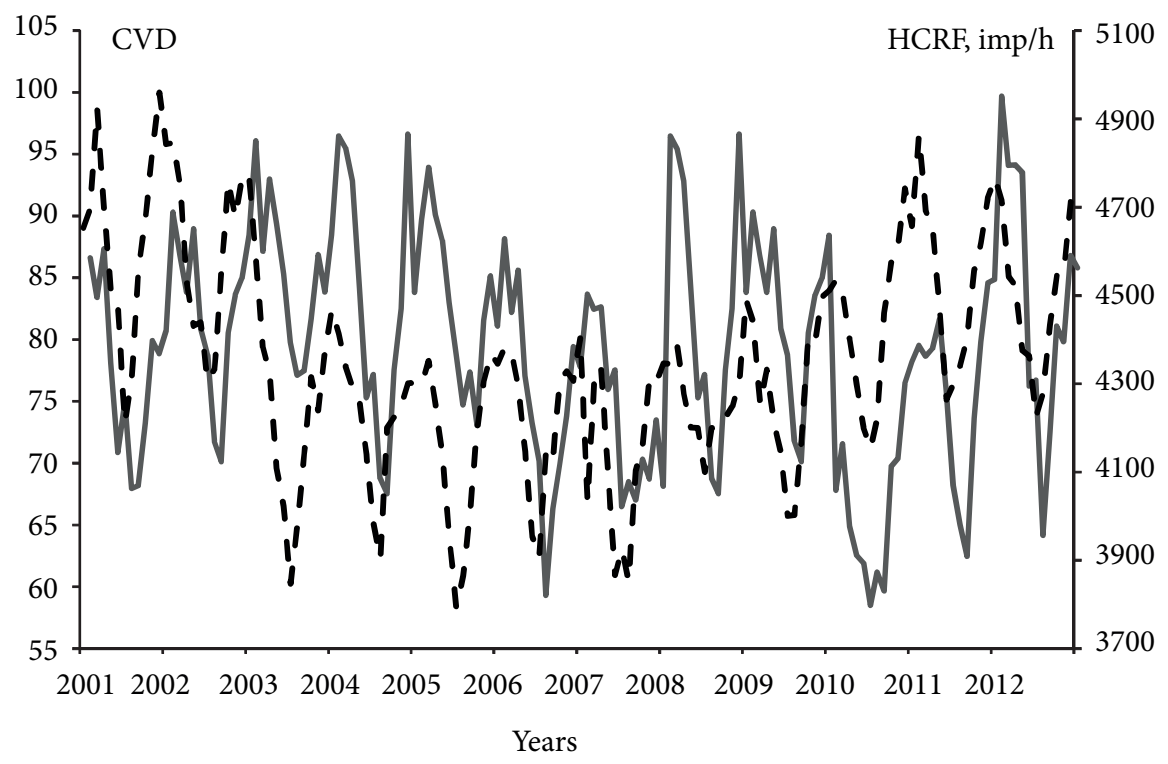

Fig. 3. Monthly average values in Vilnius in 2001-2012: in Vilnius: cardiovascular diseases (-), hard cosmic ray flux (-----)

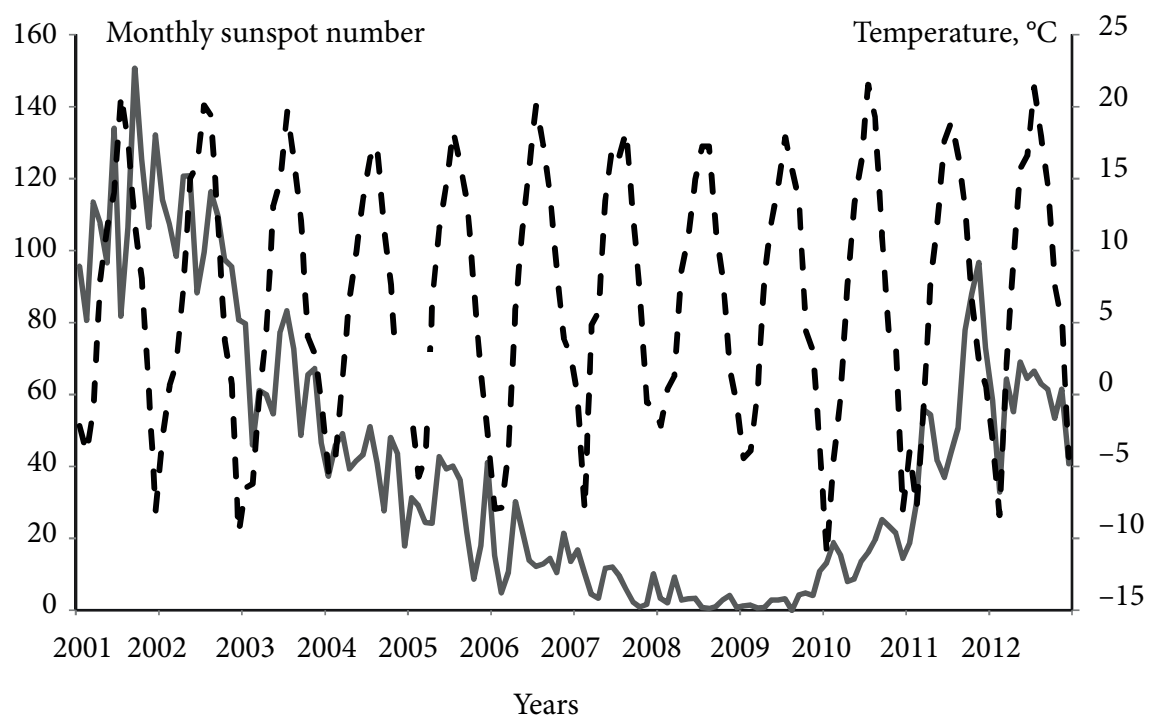

Fig. 4. Monthly average values in 2001-2012: solar spots (- ), temperature in Vilnius $(----)$ 
A some connection between them was observed only during the most solar activity, i. e. in 2001-2002 and 2011-2012. Here the values of correlation coefficients between the number of sunspots and number of CVD were in the range from 0.53 to 0.61 and in the other time (2003-2010) they were less than 0.4 .

It is necessary to point out a strong connection between the behaviour of the average monthly values of HCRF and temperature, where the correlation coefficient was -0.9 .

Therefore, in comparison of the course of average monthly data (Figs 3,4) it is possible to confirm about the existence of correlation between physical parameters and CVD numbers.

Data of obtained results during the years of maximum Sun's activity are presented in Table 1.

It should be noted that the average monthly sunspot number in 2001 was two times higher than in 2012 (Table 1).

According to data of this table that at higher activity of the Sun (2001) the number of CVD turned out to be less and average monthly temperature was lower, than in 2012. Here a seasonal cycle of average monthly value of HCRF, temperature and CVD is fixed, but there is not solar activity effect on these parameters.

The greatest practical interest puts the short-term prognosis of leaps in CVD after change of analysed physical characteristics. For instance, there wasn't found correlation between air temperature change and CVD leaps in 1-3 days. Also the connection between increase of number of sunspots and the subsequent changes of number of CVD, exceeding $10 \%$ of average monthly values wasn't registered.

Short-term predictive connection was found only between the HCRF decrease and leaps of CDV in 1-3 days. As an example the data of such connection for the years of maximum $(2001,2012)$ and minimum (2009) Sun's activity are presented in Table 2.

According to the data of this table a good predictive connection between HCRF decrease and leaps of CVD is obtained. The greatest efficiency (79\%) prognosis was found for 2009, when solar activity was minimum (average monthly number of spots was 3 ).

The minimum efficiency of short-term prognosis in 2012 was in summer and autumn months (Table 2) and average monthly temperatures were higher, than in 2001 (Table 1).

Naturally, that single connection between short-term changes of physical parameters (sunspots, temperature) and leaps in CVD doesn't exist. However, a good correlation between the decrease of HCRF, which is indirectly characterising variation of geomagnetic field, and leaps in CVD was found.

To above presented information it is necessary to add a human factor, which also has an impact on leaps in CVD. However, this impact is problematic to define from the whole external influences on human health. The example of existence of this phenomenon is presented in Table 3, where distribution of number of leaps in CVD on days of the week in 2001, 2009 and 2012 is given.

Table 1 . Average monthly values of hard cosmic ray flux (HCRF) in imp/h, temperature $\left({ }^{\circ} \mathrm{C}\right)$, cardiovascular diseases (CVD) in Vilnius and sunspot numbers in 2001 and 2012

\begin{tabular}{lcccccccc}
\hline \multirow{2}{*}{ Months } & \multicolumn{2}{c}{ HCRF } & \multicolumn{2}{c}{$\begin{array}{c}\text { Tempe- } \\
\text { rature }\end{array}$} & \multicolumn{2}{c}{ CDV } & \multicolumn{2}{c}{ Sunspots } \\
\cline { 2 - 10 } & 2001 & 2012 & 2001 & 2012 & 2001 & 2012 & 2001 & 2012 \\
\hline January & 4653 & 4768 & -2.2 & -3.3 & 86 & 99 & 96 & 58 \\
\hline February & 4697 & 4714 & -4.0 & -8.4 & 83 & 93 & 80 & 33 \\
\hline March & 4922 & 4543 & -1.0 & 2,2 & 87 & 94 & 113 & 64 \\
\hline April & 4693 & 4522 & 8.2 & 9.3 & 78 & 93 & 108 & 55 \\
\hline May & 4514 & 4375 & 11.6 & 15.8 & 70 & 76 & 97 & 69 \\
\hline June & 4481 & 4363 & 14.0 & 16.6 & 74 & 76 & 134 & 65 \\
\hline July & 4211 & 4224 & 20.9 & 21.4 & 67 & 63 & 82 & 67 \\
\hline August & 4313 & 4278 & 17.5 & 17.9 & 68 & 72 & 106 & 63 \\
\hline $\begin{array}{l}\text { Septem- } \\
\text { ber }\end{array}$ & 4561 & 4433 & 11.8 & 14.4 & 73 & 80 & 151 & 61 \\
\hline October & 4673 & 4548 & 8.0 & 7.5 & 79 & 79 & 125 & 53 \\
\hline $\begin{array}{l}\text { Novem- } \\
\text { ber }\end{array}$ & 4830 & 4550 & 0.5 & 5.0 & 78 & 86 & 106 & 61 \\
\hline $\begin{array}{l}\text { Decem- } \\
\text { ber }\end{array}$ & 4960 & 4712 & -8.1 & -4.3 & 80 & 85 & 132 & 41 \\
\hline
\end{tabular}

Table 2. CVD number exceeding the monthly average values by $10 \%$ and the number of occurrences of this increase as predicted according to a decrease in HCRF of $\geq 200 \mathrm{imp} / \mathrm{h}$ in time range of $4 \mathrm{~h}$ and more in Vilnius city in 2001, 2009, 2012. Prognosis of an increase in CVD cases is given in 1-3 days

\begin{tabular}{lcccccc}
\hline \multirow{2}{*}{ Months } & $\begin{array}{c}\text { Increase of CVD } \\
\text { numbers of 10\% above } \\
\text { the average monthly } \\
\text { value }\end{array}$ & $\begin{array}{c}\text { Number of occurrences } \\
\text { in 1-3 days intervals }\end{array}$ \\
\cline { 2 - 8 } & 2001 & 2009 & 2012 & 2001 & 2009 & 2012 \\
\hline January & 8 & 7 & 6 & 6 & 6 & 6 \\
\hline February & 3 & 8 & 8 & 3 & 5 & 7 \\
\hline March & 7 & 7 & 7 & 5 & 7 & 7 \\
\hline April & 8 & 8 & 7 & 6 & 6 & 6 \\
\hline May & 7 & 8 & 10 & 5 & 6 & 7 \\
\hline June & 8 & 10 & 8 & 6 & 10 & 2 \\
\hline July & 7 & 10 & 10 & 6 & 8 & 4 \\
\hline August & 10 & 9 & 7 & 8 & 8 & 6 \\
\hline September & 8 & 8 & 8 & 7 & 4 & 4 \\
\hline October & 7 & 6 & 9 & 4 & 4 & 8 \\
\hline November & 5 & 8 & 7 & 4 & 7 & 2 \\
\hline December & 9 & 8 & 9 & 7 & 6 & 6 \\
\hline Total & 87 & 97 & 96 & 67 & 77 & 65 \\
\hline Total, \% & & & & 77 & 79 & 68 \\
\hline & & & & & & 6 \\
\hline
\end{tabular}


Table 3. Dependence of CVD leaps number exceeding the monthly average values by $10 \%$ on days of the week during maximum $(2001,2012)$ and minimum (2009) activity of the Sun

\begin{tabular}{cccccccc}
\hline $\begin{array}{c}\text { Day } \\
\text { of } \\
\text { week } \\
\text { Years }\end{array}$ & $\begin{array}{c}\text { Mon- } \\
\text { day }\end{array}$ & $\begin{array}{c}\text { Tues- } \\
\text { day }\end{array}$ & $\begin{array}{c}\text { Wed- } \\
\text { nes- } \\
\text { day }\end{array}$ & $\begin{array}{c}\text { Thurs- } \\
\text { day }\end{array}$ & Friday & $\begin{array}{c}\text { Satur- } \\
\text { day }\end{array}$ & $\begin{array}{c}\text { Sun- } \\
\text { day }\end{array}$ \\
\hline 2001 & 24 & 16 & 13 & 14 & 7 & 4 & 9 \\
2009 & 28 & 15 & 16 & 15 & 13 & 3 & 12 \\
2012 & 26 & 16 & 20 & 15 & 13 & 3 & 3 \\
Total & 73 & 47 & 49 & 44 & 33 & 10 & 24 \\
\hline
\end{tabular}

The number of leaps in CVD in one year is approximately the same (Tables 2, 3) for different solar activities. As far as number of leaps in CVD depends on the day of week with a maximum value on Monday and minimum value on Saturday, these facts can be explained only by the human factor.

\section{Discussion}

Monitoring of HCRF was carried out continuously in Vilnius by gamma-spectrometric installation during a solar cycle 2001-2012. Measurements were carried out every $15 \mathrm{~min}$ and averaged up to one hour interval. The device reacted to muons and gamma quanta flux, i. e. to a secondary cosmic radiation near the ground surface.

The primary cosmic particles, coming from the Galaxy and partially from the Sun transfer an electric charge as far as their main part consists of protons and alphaparticles.

It is known that primary cosmic ray flux, coming from the cosmic space is isotropic. However, under the influence of the geomagnetic field, which can be unstable because of solar activity and the changes of intensity of these particles take place. Therefore, such variations have impact on secondary cosmic rays near the ground surface, which are registered by gamma-spectrometric installation. On the other hand, variations of the flux of secondary cosmic particles indirectly reflect variations in the geomagnetic field.

The variations of the geomagnetic field are affected by processes on the Sun, in particular, flares, flux of particles, ultraviolet and X-ray radiation and etc. Since solar activity is determined by the quantity of spots on its disk, that it is necessary to compare a change of their number with number of leaps in CVD.

In accordance with proposed criterion, it was found that the maximum decrease in HCRF was in the year of lowest activity of the Sun (2009), when the number of CVD leaps was the greatest. In this case, apparently, the geomagnetic field variations could be caused by the corpuscular flux or effect of ultraviolet or X-ray radiation. Here it is possible to fix the facts of diseases number change only, but not their fatal consequences.

The lowest number of ambulance calls was in the year of the greatest Sun's activity (2001), when the number of spots on its disk was 1334 and during the following maximum activity (2012) it was 996.

In a year of the minimum activity of the Sun (2009), this indicator was a little lower (980), then in 2012. It means that solar activity affects the CVD leaps, but through the various cosmic and geophysical processes. However, there was not found short-term correlation between CVD leaps in a few days after the increase in the number of sunspots.

According to the analysis of daily average values of sunspots during a whole cycle 2001-2012, it can be argued that their change was rather smooth from day to day, so the human body could adapt to these changes. This is evidenced by stable average daily number of ambulance calls. However, their average monthly values considerably change within a year as far as number of diseases depends on a season of a year (Styro et al. 2009).

It should be noted special situations when leaps in CVD are accompanied by serious consequences with hospitalization of the people having cardiovascular pathology. It happens when within several days of rather weak solar activity is observed, and after it's sharply increases within 3-4 days.

Apparently, at weak solar activity the organism "relaxes". With a significant and rapid increase in the electromagnetic influence comes a disorder of an organism, which doesn't have time to adapt to external conditions.

Such situation was at the beginning of March, 2012 from 29 February to 1-2 March, when it was observed from 14 to 20 solar spots in a day and their number increased to 85 by $6 \mathrm{March}$. If the total number of ambulance calls is slightly increase, the sharp increase in the number of hospitalization of patients takes place. The same situations had been observed at the end of March, 2001, at the middle of April 2011 and so on. At the same time there was continuous and strong HCRF decrease.

A strong negative impact on people with cardiovascular pathology has simultaneously two factors: intensive increase of solar activity within several days after the lull of the Sun and as a consequence sharp variations in the geomagnetic field. Such cases are rather rare.

Negative correlation dependence between number of CVD and temperature for monthly average values is found. In summer time at more high temperature the lesser number of calls of ambulance is observed (Fig. 4). At the same time the least values of HCRF are registered, while in winter time the inverse situation takes place (Fig. 3).

In general it is difficult to determine a main reason for such regularity. External impacts on human body have 
a regularity - the maximum in winter and the minimum in summer. Thus the organism is influenced by variations of a geomagnetic field, change of meteorological processes, etc., and within a year the distance between the Earth and the Sun changes up to $5000000 \mathrm{~km}$ that also defines efficiency of solar impact on the biosphere.

Short-term correlation between HCRF decrease and leaps in CVD in 1-3 days (Table 2) is evident, but such connection isn't observed at temperature variations.

It is necessary to pay attention to the accuracy of obtained information. If the data of solar activity, temperature and CVD can be considered as an existing facts, when registering $\mathrm{HCRF}$ it is necessary to consider a possible influence of external sources on the equipment. There are natural processes influencing the accuracy of measurement of HCRF near the ground surface. In particular thunderstorm activity, tectonic movements, changes of meteorological processes-intesinty of cyclonic or anti-cyclonic activity and etc. (Styro et al. 2009). Therefore data of HCRF require correction and specification.

For the analysis of obtained data it is necessary to take into account the human factor (Table 3), which may occur simultaneously with the other external influences on the human body. So, above described factors are only possible additive impact on people and are not the main cause of cardiovascular diseases.

Thus the cosmic and environment influence in total sometimes has a negative affect on people and especially on people with cardiovascular pathology.

It is problematic to determine the main contribution of each component of external impacts from all causes of CVD leaps.

\section{Conclusions}

It is found that variations in HCRF is short-term predictive indicator of CVD leaps. For the analysis and proof of this postulate the optimum empirical criterion was defined. Such a criterion was HCRF decrease during 4 hours and more by $200 \mathrm{imp} / \mathrm{h}$ and more when the leaps of CVD are formed in 1-3 days. Efficiency of such connection was high due to $68-79 \%$.

However there wasn't CVD leaps in 1-3 days after temperature variation or changes in the number of sunspots. Correlative connection between a course of average monthly values of HCRF, temperature, CVD and their dependence on season of year is found out. At the same time, the number of sunspots may be different which slightly varies from one to other days.

There wasn't correlation between a course of average monthly sunspot number and other parameter. So, the number of sunspots can't be an indicator of external impact on a human body. Only under certain conditions such an effect can occur, when after some "calm" for a few days (approximately constant number of spots) extends a strong increase of solar activity. However, such cases are relatively rare.

The obtained results in this paper should be considered as an established fact. The offered method of short term prognosis of CVD leaps according to HCRF decrease can be applied in practice.

\section{References}

Bi, P.; Williams, S.; Loughnan, M. 2011. The effects of extreme heat on human mortality and morbidity in Australia: implications for public health, Asia-Pacific Journal of Public Health 23(2 Suppl): 27S-36S.

http://dx.doi.org/10.1177/1010539510391644

Breus, T. K.; Baevskii, R. M.; Chernikova A. G. 2012. Effects of geomagnetic disturbances on humans functional state in space flight, Journal of Biomedical Science and Engineering 5: 341-355. http://dx.doi.org/10.4236/jbise.2012.56044

Chizhevsky, A. 1976. The Earth's echo of Solar storm. Moscow: Mysl (in Russian).

Dimitrova, S.; Stoilova, I.; Georgieva, K.; Taseva, T.; Jordanova, M.; Maslarov, D. 2009. Solar and geomagnetic activity and acute myocardial infarction morbidity and mortality, Fundamental Space Research 4: 161-165.

Ferrari, U.; Exner, T.; Wanka, E. R.; Bergemann, Ch.; MeyerArnek, J.; Hildenbrand, B.; Tufman, A.; Heumann, Ch.; Huber, R. M.; Bittner, M.; Fischer, R. 2012. Influence of air pressure, humidity, solar radiation, temperature, and wind speed on ambulatory visits due to chronic obstructive pulmonary disease in Bavaria, Germany, International Journal of Biometeorology 56: 137-143.

http://dx.doi.org/10.1007/s00484-011-0405-x

Hiltunen, L.; Ruuhela, R.; Ostamo, A.; Lönnqvist, J.; Suominen, K.; Partonen, T. 2012. Atmospheric pressure and suicide attempts in Helsinki, Finland, International Journal of Biometeorology 56: 1045-1053. http://dx.doi.org/10.1007/s00484-011-0518-2

Houck, P. D.; Lethen, J. E.; Riggs, M. W.; Gantt, D. S.; Dehmer, G. J. 2005. Relation of atmospheric pressure changes and the occurrences of acute myocardial infarction and stroke, American Journal of Cardiology 96(1): 45-51. http://dx.doi.org/10.1016/j.amjcard.2005.02.042

Lim, Y. H.; Kim, H.; Kim, J. H.; Bae, S.; Hong, Y. Ch. 2013. Effect of diurnal temperature range on cardiovascular markers in the elderly in Seoul, Korea, International Journal of Biometeorology 57: 597-603. http://dx.doi.org/10.1007/s00484-012-0587-x

Martin, S. L.; Cakmak, S.; Hebbern, Ch. A.; Avramescu, M. L.; Tremblay, N. 2012. Climate change and future temperaturerelated mortality in 15 Canadian cities, International Journal of Biometeorology 56: 605-619. http://dx.doi.org/10.1007/s00484-011-0449-y

McGuinn, L.; Hajat, S.; Wilkinson, P.; Armstrong, B.; Anderson, H. R.; Monk, V.; Harrison, R. 2013. Ambient temperature and activation of implantable cardioverter defibrillators, International Journal of Biometeorology 57: 655-662. http://dx.doi.org/10.1007/s00484-012-0591-1

Palmer, S. J.; Rycroft, M. J.; Cermack, M. 2006. Solar and geomagnetic activity, extremely low frequency magnetic and 
electric fields and human health at the Earth's surface, Surveys in Geophysics 27: 557-595.

http://dx.doi.org/10.1007/s10712-006-9010-7

Rodriquez-Taboada, E. R.; Sierra-Figueredo, P.; Figueredo, S. S. 2004. Geomagnetic activity related to acute myocardial infarctions: relationship in a reduced population and time interval, Geofisica Internationale 43(2): 265-269.

Styro, D.; Usovaitè, A.; Damauskaite, J.; Juozulynas, A. 2009. Leaps in cardiovascular diseases after a decrease of hard cosmic ray flux and atmospheric pressure in Vilnius city in 2004-2007, International Journal of Biometeorology 53: 471477. http://dx.doi.org/10.1007/s00484-009-0234-3

Styro, D.; Chuchelis, A.; Usovaite, A.; Damauskaite, J. 2008. On possibility of short-term prognosis of cyclonic activity aftereffects in Vilnius by variation of hard cosmic ray flux, Journal of Environmental Engineering and Landscape Management 16: 159-167. http://dx.doi.org/10.3846/1648-6897.2008.16.159-167

Styro, D.; Damauskaite, J.; Beliajev, A. 2011. On the short - term prognosis of anticyclonic formations in Vilnius by the hard cosmic ray flux variation, Journal of Environmental Engineering and Landscape Management 19: 234-243. http://dx.doi.org/10.3846/16486897.2011.602557

Styro, D.; Gaspariūnas, J.; Usovaitè, A. 2004. Peculiarities of hard cosmic radiation variations near the ground surface in accordance with geomagnetic activity changes, Journal of Environmental Engineering and Landscape Management 12: 96-102.
Styro, D.; Usovaitė, A.; Damauskaitė, J.; Juozulynas, A.; Lukšiené, A. 2007. A On connection between hard cosmic ray flux, atmospheric pressure variation and the leaps of cardiovascular diseases in Vilnius in 2002, Acta Medica Lituanica 14: 205-209.

Styro, D.; Usovaitè, A.; Gaspariūnas, J.; Juozulynas, A. 2005. On the connection between hard cosmic ray flux variations and changes in cardiovascular disease in Vilnius city, International Journal of Biometeorology 49: 267-272. http://dx.doi.org/10.1007/s00484-004-0230-6

Stoupel, E.; Tamoshiunas, A.; Radishauskas, R.; Bernotiene, G.; Abramson, E.; Israelevich, P. 2012. Acute myocardial infarction (AMI) (n-11026) on days of zero geomagnetic activity (GMA) and the following week: differences at months of maximal and minimal solar activity (SA) in solar cycles 23 and 24, Journal Basic Clinical Physiology and Pharmacology 23: 5-9. http://dx.doi.org/10.1515/jbcpp-2012-0001

Sunspot data files. 2013. Sunspot data files $20010101-201212$ 31 [online], [cited 21 March 2013]. Available from Internet: ftp://ftp.ngdc.noaa.gov/STP/SOLAR_DATA/.

Vencloviene, J.; Babarskiene, R.; Slapikas, R.; Sakalyte, G. 2013. The association between phenomena on the Sun, geomagnetic activity, meteorological variables, and cardiovascular characteristic of patients with myocardial infarction, International Journal of Biometeorology 57: 797-804. http://dx.doi.org/10.1007/s00484-012-0609-8

Dmitrijus STYRO. Dr Habil., Prof., Dept. of Physics, Vilnius Gediminas Technical University (VGTU). Doctor Habil. of Natural Sciences (physics and mathematics), Sevastopol Marine Hydrophysical Institute (1984). Doctor of Natural Sciences (physics and Mathematics), Vilnius University (1968). Publications: author of over 250 scientific publications. Conferences: paticipant of over 120 international and national conferences. Research interests: nuclear hydrophysics, radioecology and prediction of anomalous effects on the Earth.

Ana USOVAITE. Dr, associate professor in Department of Graphical Systems, Vilnius Gediminas Technical University (VGTU). Doctoral degree in the field of technology sciences Publications: author of over 30 scientific publications. Conferences: participant of over 15 international and national conferences. Research interests: radioecology and prediction of anomalous effects on the Earth. 